\section{P598 TRAUMA OF THE LIVER IN CHILDREN WITH FIREARM INJURIES DUE TO WAR: WHEN IT SHOULD BE OPERATED?}

Mehmet Çelikkaya, Ahmet Atıı, Çiğdem El*, Bülent Akçora. Mustafa Kemal Universitiy, Hatay, Turkey

10.1136/archdischild-2019-epa.932

Aim The patients with liver injury should be considered multidisciplinary and the decision of operation should be decided according to the patient's clinic and hemodynamic stability. In this study, we aimed to present treatment management and appropriate operation time in children with liver injury due to war.

Methods Between 2010-2017, patients who be followed in pediatric surgery clinic with liver injuries due to firearm were examined retrospectively. Patients; according to age, gender, type of injury, accompanying trauma, treatment modality and mortality were evaluated.

Results 13 patients were injured with shrapnel, 7 patients had blast effect injury. The mean pediatric trauma score of patients was 5 , the mean pediatric trauma score of 6 patients who died was 3.11. Liver suturing was performed in 2 patients due to bleeding. A segmentectomy was performed in a patient with active bleeding in segment 7 . Bleeding was stopped by binding the branches of the hepatic artery. 2 patients who were operated in Syria and applied packing due to unstoppable bleeding were referred to Turkey. One patient with vena cava inferior injury died due to excessive blood loss and instability at the time of admission and 6 patients died due to accompanying head trauma and/or multiple body trauma.

Conclusion The main purpose in emergency operations is stopping the bleeding. Rarely though, suturing or even segment resection in the bleeding area may require.

\section{P599 ABSTRACT WITHDRAWN}

\section{P601 TAKAYASU ARTERITIS IN PEDIATRICS}

${ }^{1}$ Bayene Maalej, 'Sahar Trichili, Imen Moalla 1, 'Faiza Safi, ${ }^{1}$ Manel Weli, ${ }^{2}$ Manel Charfi* ${ }^{2}$ Abdelatif Gargouri, ${ }^{3}$ Feten Haj kacem, ${ }^{3}$ Mohamed Abid, ${ }^{1}$ Lamia Gargouri, ${ }^{1}$ Abdelmajid Mahfouth. ${ }^{1}$ Emergency Pediatric Service, Sfax, Tunisia; ${ }^{2}$ Neonatology Service, Sfax, Tunisia; ${ }^{3}$ Endocrinology Service, Sfax, Tunisia

\subsection{6/archdischild-2019-epa.933}

Introduction Takayasu arteritis is an idiopathic chronic granulomatous panarteritis predominantly affecting the aorta and its main branches. The diagnosis is based on a set of clinical, biological and radiological criteria.

Observation Thes are two girls, averag age 12 years. They presented a decrease in visual acuity and high blood pressure. One of the two girls had right radial and brachial pulse abolished. In the two cases a bilateral edema was objectified. An hypokalemia was noted in one case. The angio scanner showed a stenosis of the right subclavian artery with stenosis of the aortic arch extended to both renal arteries, with complete occlusion of the right right renel artery. For the other child, the aortic angiocan showed non-stenosing focal thikening of the descendeng aorta, with pre stenosis occlusive from the origin of the right renel artery. There was no brain damage in the two cases. One of the two girls was treated with a high-dose corticosteroid with methotrexate and an antihypertensive drug. The other child was treated with potassium supplementation in addition to antihypertensive treatment.

Conclusion Takayasu arteritis is a chronic vasculitis of unknown etiology. Rare in children, it is a worldwide disease with significant morbidity and mortality.

\section{P602 EATING HABITS, PSYCHICAL ACTIVITY AND SELF- PERCEIVED HEALTH AS DETERMINANTS OF QUALITY OF LIFE OF ADOLESCENTS}

${ }^{1,2}$ Saša Missoni*, ${ }^{1}$ Eva Anđela Delale, ${ }^{1}$ Natalija Novokmet, 'Dubravka Havaš Auguštin, ${ }^{3}$ Sanja Musić Milanović, ${ }^{4}$ Vesna Jureša. ${ }^{1}$ Institute for Anthropological Research, Zagreb, Croatia; ${ }^{2}$ J. J. Strossmayer University, School of Medicine, Osijek, Croatia; ${ }^{3}$ Croatian Institute of Public Health, Zagreb, Croatia; ${ }^{4}$ School of Medicine, University of Zagreb, Croatia

\subsection{6/archdischild-2019-epa.934}

Perceived quality of life (QoL) in adolescents can be useful in identifying their subgroups at risk of engaging in health-compromising behaviors. Establishing healthy nutritional behaviors and physical activity is important during adolescence, since habits established in this period often persist into adulthood. This study gives insights from the Croatian Health Study of School Children and Adolescence, with focus on QoL of adolescents. The aims of the study were to investigate eating habits, psychical activity and some aspects of self-assessed health of adolescents as potential predictors of their QoL. The sample consisted of 482 high-school students 16-19 years old (243 girls), who participated in project in 2013/2014. Adolescents' assessment of food frequency consumption, extra-curricular physical activities, frequency of health difficulties within last six month and QoL (WHOQOL-bref) were used.

Boys reported higher levels of QoL than girls in Physical health and Psychological domains. The greatest variance was explained in Physical health for boys (31.5\%) and girls $(43.2 \%)$ and smaller amounts in Psychological domain (18.5\% boys, 32\% girls), Social relationship (17.1\% boys, $19.1 \%$ girls) and in Environmental health $(16.4 \%$ boys, $21.4 \%$ girls). Structure of predictors differed for girls and boys in all four domains. The greatest variance was explained by self-perceived health in both boys and girls. More frequent emotional health difficulties within last six months were associated with smaller QoL in all domains, except in boys in Environmental domain. Greater adolescent's overall perception of their health was associated with higher QoL in all domains, except in Social relationship domain in both boys and girls. More frequent physical health difficulties within last six months were associated with smaller Physical QoL in both boys and girls. Frequency of healthy meals within last seven days predicted Physical QoL in girls; contrary, more frequent unhealthy meals were associated with better Social relationship in boys. Higher frequency of leisure time physical activities was associated with better results in Social and Environmental domain in girls and more frequent physical activities within last seven days were associated with better Psychological and Social relationship QoL in boys.

The selected set of predictors significantly predicted adolescents' QoL, especially Physical and Psychological domain. These findings support hypothesis that eating habits, physical activity and some aspects of self-assessed health could contribute to QoL of adolescents. Additional variables and predictors 